\title{
O impacto da pandemia sobre o fazer da universidade
}

\author{
The impact of the pandemic on university \\ routine and new ways of doing
}

\author{
Atson Carlos de Souza Fernandes ${ }^{1}$ (i) \\ Patricia Gomes Cerqueira Fernandes ${ }^{2}$ (1)
}

1Autor para correspondência. Escola Bahiana de Medicina e Saúde Pública (Salvador); Universidade do Estado da Bahia (Salvador). Bahia, Brasil. atsonfernandes@yahoo.com.br

${ }^{2}$ Centro Universitário Jorge Amado (Salvador). Bahia, Brasil. pattfernandes@yahoo.com.br

\begin{abstract}
A pandemia nos impôs a necessidade de se reinventar, buscando soluções que atendessem aos anseios da sociedade, em especial ao da manutenção do ensino em meio às restrições impostas como medidas de contenção ao avanço do SARSCoV-2. ${ }^{1}$ Neste cenário, a tecnologia se tornou um grande aliado da academia, evidenciando sua importância enquanto instrumento indispensável no modelo ensino-aprendizagem presente e futuro. De repente, fomos impelidos a um processo acelerado de transformação que, em condições normais, poderia se estender por, pelo menos, 5 anos. Em meio a tantas mudanças em um curto espaço de tempo, quais impactos podemos esperar na formação dos futuros egressos profissionais?
\end{abstract}

Face a uma crise sanitária sem precedentes nos últimos 100 anos, desde março de 2020 as universidades brasileiras foram desafiadas a repensar e ressignificar seu modelo de ensino, redimensionando um novo universo de formação em meio a rígidas restrições de acesso da comunidade acadêmica aos espaços físicos institucionais. ${ }^{2-4}$ Variáveis como tamanho, localização, modelo de gestão e ferramentas tecnológicas de suporte, determinaram respostas diferentes de rapidez e capacidade de adaptação das diversas Instituições de Ensino Superior (IESs) no país.
Apesar dos prejuízos causados pelas restrições de acesso a espaços físicos de treinamento (laboratórios, ambulatórios, etc), importantes para o desenvolvimento de habilidades e competências atitudinais, a necessidade de se reinventar, se adaptar, colaborar, tornar-se resiliente e de incorporar tecnologias na nova forma de fazer e aprender, trouxe valores significativos para a garantia de sucesso do novo profissional do século 21. De acordo com a previsão da Dell Technologies ${ }^{5}$, até 2030 haverá grandes mudanças nos postos de trabalho que serão ocupados pelas gerações $Z$ e Alpha que deverão trazer consigo novas habilidades, para além daquelas desenvolvidas no modelo tradicional de ensino.

O ensino remoto permitiu avançarmos em novas metodologias ativas de ensino-aprendizagem a exemplo da aula invertida (flipped classroom) ${ }^{6}$, oportunizando um ambiente de discussão mais rico e dinâmico nos encontros telepresenciais, além de oferecer aos alunos o conforto do acesso a vídeo-aulas e outros recursos digitais em dias e horários de melhor conveniência, de acordo com sua própria rotina de vida. 
Nesse quesito, podemos nos perguntar se faz sentido retrocedermos ao modelo de sala de aula tradicional passada a pandemia, semelhante ao que praticávamos no início do século $X X$, impondo as limitações e dificuldades da presença em ambientes físicos, sujeitando os alunos a variáveis como trânsito, condições climáticas, gastos com transporte, riscos de infecção cruzada, dentre outros. Por outro lado, condições técnicas individuais como equipamentos adequados e acesso a rede de internet de qualidade são fatores determinantes para o sucesso desse novo modelo híbrido (blended learning) de formação. ${ }^{-1-8}$

Outro importante avanço tem sido a oportunidade de treinamento e ambientação dos futuros profissionais com os recursos e possibilidades do atendimento telepresencial, autorizado em caráter emergencial pela Lei Federal no. 13.989/2020 de 15 de abril de 20209, método que tende a se consolidar e expandir no mercado na área da saúde, democratizando o acesso da população a profissionais de diversas áreas, até então só possível a partir de deslocamentos, por vezes distantes, e custos elevados. Com o crescimento dos recursos tecnológicos, acesso a informação, inteligência artificial e internet de alta velocidade, será possível em breve o paciente ter encontros presenciais com o profissional da saúde apenas em situações que requeiram realização de procedimentos.

O novo momento também continuará impondo às universidades a necessidade de se reinventar acadêmica e administrativamente. Em instituições mais céleres no processo de reestruturação, novos fluxos de trabalho foram criados possibilitando atendimento remoto e eficaz à sua comunidade acadêmica, a exemplo de processos seletivos, realização de bancas de defesa de trabalho de conclusão de curso (TCC), mestrado e doutorado, permitindo, inclusive, dada a ausência de limitação física, maior número de participantes nos diversos ambientes virtuais, além da participação de membros de banca de outras regiões do país ou mesmo fora do país, antes difícil ou mesmo impossível dada as dificuldades de deslocamentos e custos elevados.

Da mesma forma, assuntos de natureza administrativa passaram pelo processo de transformação, fazendo surgir uma outra discussão quanto à permanência ou não do trabalho remoto ou home office. $\frac{10}{}$ Uma vez que se tornou possível o atendimento pleno e eficaz, remotamente, por alguns setores acadêmico-administrativos da universidade, o que justificaria retornar à oferta de serviços presenciais? Se antes muitas instituições discutiam suas demandas por ampliação de espaços físicos, possivelmente muitas agora passarão a redimensionar espaços ociosos, inclusive com redução de custos operacionais.

O momento, porém, requer sensibilidade de leituras individuais e coletivas. Ainda estamos todos em processo de adaptação ao novo e algumas questões precisão ser investigadas e discutidas, a exemplo do nível de engajamento dos estudantes no processo de ensino-aprendizagem, desenvolvimento de habilidades sócio-emocionais, ou soft-skills, impactadas pelo distanciamento físico, capacitação e condições de trabalho para exercício da docência e atividades técnicoadministrativas em formato digital,....

Ainda não temos respostas para tantas perguntas já presentes, e outras que ainda irão surgir. E esse também será mais um desafio para a academia: estruturar modelos de estudo e pesquisas para identificar os impactos das mudanças, mantendo o equilíbrio acadêmico-administrativo para evitar retrocessos, mas avançar também com cautela para que os ganhos sejam reais, seguros e transformadores, trazendo impactos positivos para todos os envolvidos nesse "novo normal". Mais importante, não podemos desperdiçar a grande oportunidade que temos de repensar o modelo de educação que queremos, e precisamos, para os desafios do novo século.

\section{Conflitos de interesses}

Nenhum conflito financeiro, legal ou político envolvendo terceiros (governo, empresas e fundações privadas, etc.) foi declarado para nenhum aspecto do trabalho submetido (incluindo, mas não se limitando a subvenções e financiamentos, participação em conselho consultivo, desenho de estudo, preparação de manuscrito, análise estatística, etc.).

\section{Referências}

1. Li Q, Guan X, Wu P, Wang X, Zhou L, Tong Y, et al. Early Transmission Dynamics in Wuhan, China, of Novel Corona-virusInfected Pneumonia. N Engl J Med. 2020;382(13):1199-207. http:// doi.org/10.1056/NEJMoa2001316 
2. Bennardo F, Buffone C, Fortunato L, Giudice A. COVID-19 is a challenge for dental education-A commentary. Eur J Dent Educ. 2020;24(4):822-24. http://doi.org/10.1111/eje.12555

3. Burki TK. COVID-19: consequences for higher education. Lancet Oncol. 2020;21(6):758. http://doi.org/10.1016/S14702045(20)30287-4

4. Portaria $n^{\circ} 343$, de 17 de março de 2020 (Brasil). Dispõe sobre a substituição das aulas presenciais por aulas em meios digitais enquanto durar a situação de pandemia do Novo Coronavírus - COVID-19. [Internet]. Diário Oficial da União. 2020. [citado em 2020 nov. 28]. Disponível em: https://www.in.gov.br/en/web/ dou/-/portaria-n-343-de-17-de-marco-de-2020-248564376

5. Integre TI. 85\% das profissões que existirão em 2030 ainda não foram inventadas, segundo estudo da Dell Technologies [Internet]. Integre TI. [citado em 2021 jun 06] Disponível em: http://www.integreti.com.br/novidades/85-das-profissoes-queexistirao-em-2030-ainda-nao-foram-inventadas-segundo-estudoda-dell-technologies/

6. Gianoni-Capenakas S, Lagravere M, Pacheco-Pereira C, Yacyshyn J. Effective-ness and Perceptions of Flipped Learning Model in Dental Education: A Systematic Review. J Dent Educ. 2019;83(8):935-45. http://doi.org/10.21815/JDE.019.109
7. Partridge H, Ponting D, MCcay M. Good Practice Report: Blended Learning [Internet]. São Francisco: Creative Commons; 2011. Disponível em: https://eprints.qut.edu.au/47566/1/47566. pdf

8. Appenzeller S, Menezes FH, Santos GG, Padilha RF, Graça HS, Bragança JF. Novos Tempos, Novos Desafios: Estratégias para Equidade de Acesso ao Ensino Remoto Emergencial. Rev Bras Educ Med. 2020;44(1):e155. https://doi.org/10.1590/19815271v44.supl.1-20200420

9. Lei n. 13.989, de 15 de abril de 2020 (Brasil). Dispõe sobre o uso da telemedicina durante a crise causada pelo coronavírus (SARSCoV-2). [Internet]. Diário Oficial da União. 2020 abr 16. Disponível em: https://www.in.gov.br/en/web/dou/-/lei-n-13.989-de-15-deabril-de-2020-252726328

10. Aranha Neto MO. Artigo: O benefício do home office da pré à pós pandemia [Internet]. Grupo Mídia. [citado em 2021 jun 07] https://grupomidia.com/quemrealiza/artigo-home-office-pre-pospandemial 